\title{
The Relative Importance of Clouds and Sea Ice for the Solar Energy Budget of the Southern Ocean
}

\author{
MELANiE F. FitZPATRICK \\ Department of Earth and Space Sciences, University of Washington, Seattle, Washington \\ STEPHEN G. WARREN \\ Department of Earth and Space Sciences, and Department of Atmospheric Sciences, University of Washington, Seattle, Washington
}

(Manuscript received 14 March 2006, in final form 20 June 2006)

\begin{abstract}
The effects of clouds and sea ice on the solar radiation budget are determined for the Southern Ocean around Antarctica between latitudes $50^{\circ}$ and $80^{\circ} \mathrm{S}$. Distributions of cloud optical depth are used, together with distributions of surface albedo, to estimate the geographical and seasonal variations of shortwave irradiance and cloud radiative forcing at the surface, both for the present climate and for altered surface and cloud conditions. Poleward of $68^{\circ} \mathrm{S}$ in spring, ice causes a greater reduction of solar energy input to the surface than does cloud. However, in summer the clouds are more important than ice at all latitudes in the Southern Ocean.

In the present climate the clouds are optically thicker over open water than over sea ice, suggesting a possible negative feedback if the sea ice area shrinks with climatic warming. Compared to the present climate in spring, removing sea ice results in an increase in irradiance reaching the ocean surface, regardless of the type of cloud remaining. However, in summer the removal of ice results in higher irradiance at the surface only if clouds remain unchanged. If clouds become as thick as those presently over the ocean at $55^{\circ}-60^{\circ} \mathrm{S}$, irradiance reaching the ocean surface in summer decreases poleward of $65^{\circ} \mathrm{S}$.
\end{abstract}

\section{Introduction}

The Southern Ocean around Antarctica is a large region of potential importance for global climate change. This region is seasonally covered by sea ice with variable thickness and variable snow cover. The sea ice at its maximum extent occupies an area of ocean larger than the Antarctic continent, but about $85 \%$ of the ice melts away by the end of summer each year. Sea ice albedo has been identified as a major positive feedback in climate change (Manabe and Stouffer 1980; Holland and Bitz 2003; Hall 2004). The Southern Ocean is also one of the cloudiest regions on earth, so its solar energy budget is affected by variations of both clouds and sea ice. Compared with other areas of the world, knowledge of clouds is sparse over the Antarctic region, particularly over the ocean (Pavolonis and Key 2003; Qu and Hall 2005). In this study, we use surface-

Corresponding author address: Melanie F. Fitzpatrick, P.O. Box 159, South Hobart, 7004, Australia.

E-mail: fitz@atmos.washington.edu based measurements to quantify the contributions of clouds and sea ice to the shortwave radiation budget. In recent years, much work on this topic has been published using data from the International Satellite Cloud Climatology Project (ISCCP), Clouds and the Earth's Radiant Energy System (CERES), and its predecessor the Earth Radiation Budget Experiment (ERBE) (Ramanathan et al. 1989; Wielicki et al. 1996; Rossow and Dueñas 2004; Raschke et al. 2005). However, estimation of cloud coverage and cloud radiative properties in the polar regions from satellites remains challenging due to the difficulty of detecting clouds over snow and ice surfaces (e.g., Li and Leighton 1991). Thus it is important to have surface-based measurements of cloud cover and radiative properties to compare with satellite-derived datasets.

In our earlier work (Fitzpatrick et al. 2004, hereafter FBW04), a method was developed to infer cloud information from measurements of downward broadband solar irradiance using pyranometers. A multilevel spectral radiative transfer model was used to develop a simple but accurate parameterization relating cloud

DOI: $10.1175 / J C L I 4040.1$ 
transmittance "trc" to cloud optical depth $\tau$, surface albedo $\alpha$, and solar zenith angle $\theta$. We define trc as simply the ratio of downward irradiance under cloud to that measured under clear sky at the same solar zenith angle. The parameterization gives rms errors of only $1 \%-2 \%$ when compared to trc computed by the radiative transfer model. For large quantities of data, using the parameterization avoids time-consuming iterative solutions of the radiative transfer equation for each irradiance measurement. We then applied this parameterization to measurements from voyages of the RSV Aurora Australis (AA) in the Southern Ocean between 1991 and 2002 (Fitzpatrick and Warren 2005, hereafter FW05). Using surface albedo estimates, we obtained instantaneous cloud radiative forcing (CRF) and effective cloud optical depth $\tau$. Frequency distributions of effective cloud optical depth were fitted by decaying exponentials for latitudes $50^{\circ}-70^{\circ} \mathrm{S}$. The optical depth is "effective" in that it is calculated assuming a horizontally homogeneous overcast cloud consisting of liquid water droplets with a given effective radius (for a complete description see FW05). This derived quantity $\tau$ is an intermediate quantity for use in radiation computations, not an end in itself. It is designed to be used to compute what the transmittance of the same cloud field would be under different conditions of solar illumination and surface albedo than those under which the transmittance was measured. In this paper we use it together with regional climatologies of cloud cover and surface albedo to compute the solar transmittance for all seasons, for latitudes $50^{\circ}-80^{\circ} \mathrm{S}$. A similarly defined effective optical depth has been used previously, for example, by Barker et al. (1998).

In this paper, we use the distributions of effective cloud optical depth from FW05, together with distributions of surface albedo in the Southern Ocean, to estimate the geographical and seasonal variations of shortwave (SW) cloud radiative forcing at the surface for the ocean around Antarctica. We then calculate what the values of SW irradiance and SW cloud forcing would be for different surface and cloud conditions. We remove either ice or clouds from the computations to determine their relative importance. In the present climate the clouds are optically thicker over open water than over sea ice, suggesting a possible negative feedback on climate change. To investigate this hypothetical feedback, the changes to the solar energy budget caused by removing sea ice are computed both with and without cloud thickness changes.

The present study is limited to shortwave radiation, so it is only half of the radiation story. For example, when Minnett (1999) considered both shortwave and longwave radiation for the Arctic, he found that for high solar elevation angle clouds cool the surface, at intermediate solar elevation the surface radiation budget is insensitive to changes in cloud, and at low sun the surface is heated by the presence of clouds. In the shortwave budget, considered here, clouds always cause a reduction of the radiation absorbed at the surface.

Using ERBE data from satellites, Yamanouchi and Charlock (1997) found that clouds masked the effect of sea ice on planetary albedo by one-half or more. They also noted the importance of sea ice in the radiation budget, finding that "the radiative effect of sea ice is similar to, but less than, clouds over open water." In this present study, we try to quantify these independent effects of clouds and sea ice in the shortwave spectrum using the ship observations of cloud transmittance and surface albedo.

\section{Frequency distributions of cloud optical depth, surface albedo, and solar zenith angle}

To determine geographical and seasonal variations in the surface SW radiation budget, we require frequency distributions of cloud properties and surface albedo for each season and each geographical grid box. Because we are using radiation measurements from the voyages of only one ship, we must determine whether the cloud conditions sampled on those voyages are representative of the long-term cloud climatology. On all voyages of the AA from 1990 to 2002, trained observers recorded cloud type and amount at 3-hourly intervals. Those voyages covered all longitudes around Antarctica. The data are archived both by the Commonwealth Bureau of Meteorology and by the Comprehensive OceanAtmosphere Data Set (COADS) (Woodruff et al. 1998; Worley et al. 2005). In Fig. 1, total cloud cover from these voyages is compared with that obtained from all ship reports for the 30-yr period from 1952 to 1981 (Warren et al. 1988, map 112). Figure 1 shows that the clouds over the AA, whose radiative properties we analyze here, do appear to be representative of the climatological average cloud cover at all longitudes in the two zones $50^{\circ}-60^{\circ} \mathrm{S}$ and $60^{\circ}-70^{\circ} \mathrm{S}$. Typically, the Southern Ocean region displays average total cloud cover exceeding 80\% (Warren et al. 1988, maps 6-9), well above the global average of $64 \%$ (Hahn et al. 1995). In Fig. 1, and in several of the other figures, we show results only for the spring and summer seasons because they dominate the solar energy budget. In autumn and winter there are far fewer radiation measurements and cloud reports, but there is also very little sunlight. The seasons are defined as follows: spring [September-November (SON)], summer [December-February (DJF)], autumn [March-May (MAM)], and winter [June-August (JJA)]. 


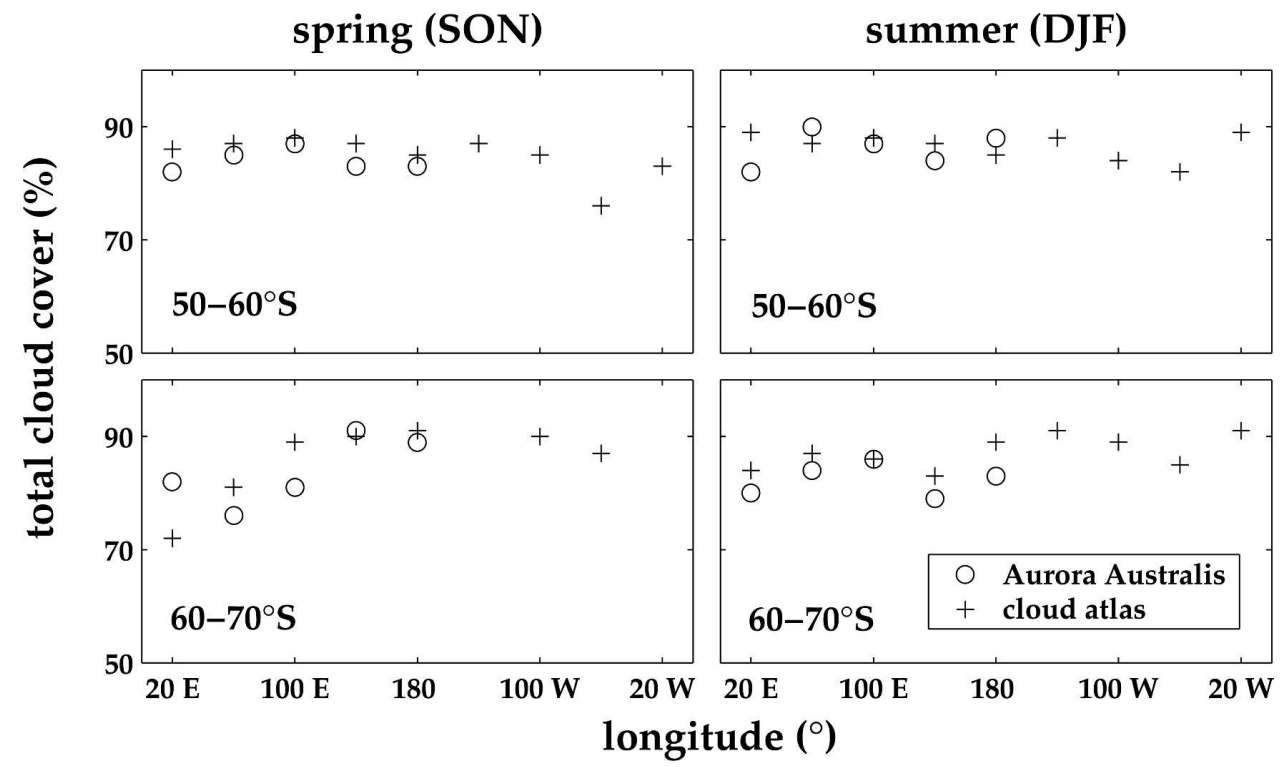

FIG. 1. Total cloud cover from ship-based meteorological observations of RSV Aurora Australis voyages between 1991 and 2002, grouped into $10^{\circ} \times 40^{\circ}$ latitude-longitude grid boxes, compared with total cloud cover derived from all ship-based observations from 1952 to 1981 ("cloud atlas," Warren et al. 1988).

We expected that the cloud cover in a region would be greater if sea ice was absent. In visual observations from AA, the average cloud cover is indeed lower over sea ice $(77 \%)$ than over open ocean $(84 \%)$, but this difference appears to be primarily a latitudinal variation. When ice-covered and open-ocean areas at the same latitude were compared, their average reported cloud covers agreed to within $1 \%$. In extrapolating our cloud transmission measurements to regions and seasons of the Antarctic not sampled by the AA, we therefore assume zonal symmetry. This is simply a default assumption in the absence of information; in reality we expect that there will be zonal asymmetry in cloud properties. When we compute irradiances for hypothetical climates without sea ice in section 4 , in one scenario we do increase the cloud optical thicknesses.

\section{a. Cloud optical depth}

In earlier work we used 18 of the voyages of the AA between 1991 and 2002 to obtain frequency distributions of effective cloud optical depth as a function of latitude for different surface types and seasons (Fig. 14 of FW05). We found that the observed distributions could be fitted by exponential functions:

$$
f(\tau)=\frac{1}{\tau_{c}} \exp \left(-\tau / \tau_{c}\right),
$$

where $\tau_{c}$ is a characteristic mean optical depth that varies with latitude. [We also tried gamma distributions (after Barker 1996 and Kato et al. 2005) and found that the shape parameter varied from 0.7 to 1.6 , averaging 1.0 over the different latitude bands. Because of the noise in our histograms, we cannot conclude that there is a systematic variation of the shape of the distribution with latitude. We therefore used the functional form of Eq. (1), which assumes a shape parameter of 1.0, for all latitudes.] We attempted to find distinct values of $\tau_{c}$ for the different cloud types, but the number of observations was insufficient to do that. We also plotted separate distributions for the different seasons, but again the distributions were noisy. We therefore grouped all observations independent of season and cloud type, classified only by latitude, and fitted exponentials to those distributions. Keeping $\tau_{c}$ constant through the year is a default assumption in the absence of information. In reality, we expect that cloud optical thickness will not be constant.

The thickest clouds are found at $55^{\circ}-60^{\circ} \mathrm{S}$, slightly north of the peak of zonal average cloud cover (Warren et al. 1988, Fig. 10), and $\tau_{c}$ decreases both to the north and south of this zone. Proceeding southward from the zone $55^{\circ}-60^{\circ} \mathrm{S}$, with $\tau_{c}=24$, the optical depths decrease systematically, to $\tau_{c}=17$ for $60^{\circ}-65^{\circ} \mathrm{S}$ and $\tau_{c}=11$ for $65^{\circ}-70^{\circ} \mathrm{S}$ (Fig. 14 of FW05). We do not have sufficient observations of trc for the sea ice region south of $70^{\circ} \mathrm{S}$, but an interpolation is possible. The optical depths are 


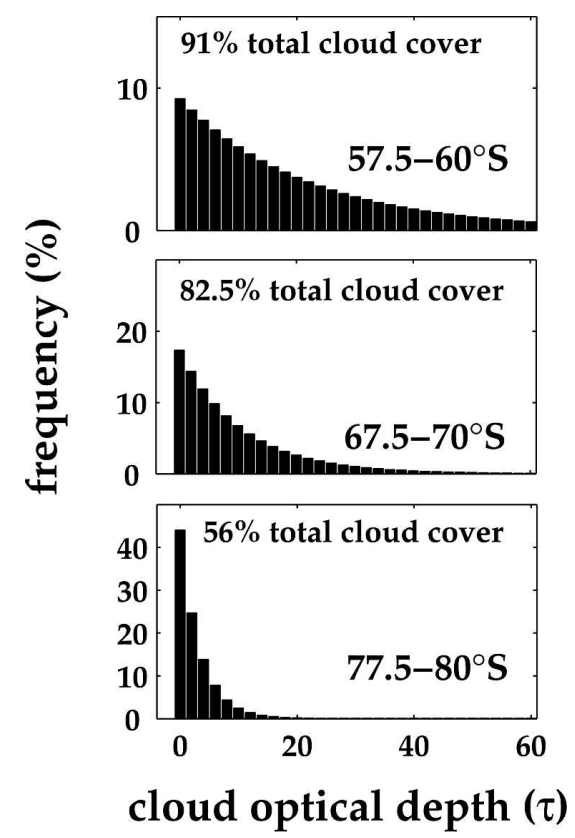

FIG. 2. Zonal-average distributions of effective cloud optical depth described by the exponential fit $f(\tau)=\tau_{c}{ }^{-1} \exp \left(-\tau / \tau_{c}\right)$, where $\tau_{c}$ is a characteristic optical depth for each latitude given by Eq. (2). Calculations were made for all 12 latitude intervals in $2.5^{\circ}$ steps from $50^{\circ}$ to $77.5^{\circ} \mathrm{S}$; three examples are shown here.

very small over the Antarctic interior, with $\tau_{c}=1$ at the South Pole (Fig. 10 of Mahesh et al. 2001). Using the three values from $55^{\circ}$ to $70^{\circ} \mathrm{S}$ together with the South Polar value, a good fit was obtained for $\tau_{c}$ as a quadratic function of latitude:

$$
\tau_{c}=0.685+0.02185(90-\phi)^{2},
$$

where $\phi$ is the central latitude of a $2.5^{\circ}$ zone. This function is used to generate frequency distributions of $\tau$ for the latitude zones $70^{\circ}-80^{\circ} \mathrm{S}$. Some examples of the frequency distributions used in the analysis below are shown in Fig. 2. The first bin, at $\tau=0$, we call "clear sky," but it does not mean that the sky is completely free of clouds. Observations fall into this bin whenever the solar irradiance equals or exceeds the value for completely clear sky; that is, whenever the direct solar beam is not blocked by a cloud. As a field of scattered clouds moves across the sky, some of the pyranometer measurements will therefore be characteristic of clear sky and others of an overcast or near-overcast cloud. This point is further discussed in section 3 of FW05. The bin size in Fig. 2 is $\Delta \tau=2$; this size gave the total cloud cover fraction in agreement with values in Fig. 1 in that the frequency in the bin at $\tau=0$, when added to the fractional cloud cover, sums to approximately $100 \%$ in each latitude zone.

\section{b. Albedo distributions}

A seasonal and geographical climatology of surface albedo for the Antarctic sea ice zone was developed by Brandt et al. (2005) using (i) spectral albedo measurements of each ice type; (ii) about 10000 visual reports from Antarctic research and supply ships of the areal coverage of each ice type, from the project on Antarctic Sea Ice Processes and Climate (ASPeCt: Worby 1999); and (iii) the area fractions of ice and water within the sea ice zone, from satellite passive microwave measurements (Comiso 1986, 2002). Albedos were presented for Advanced Very High Resolution Radiometer (AVHRR) channels, and for visible and near-infrared bands used in general circulation models, as well as broadband solar albedos. In this work we use the broadband solar albedos. The report of Brandt et al. gave average values only, for five longitudinal sectors in each $2.5^{\circ}$ latitude zone. For our work we need frequency distributions rather than averages, because the radiative interactions between clouds and surface are nonlinear, and we need values for each $40^{\circ}$ of longitude rather than just five longitudinal sectors. We therefore use intermediate results supplied by R. E. Brandt and A. P. Worby (2004, personal communication) that were used in the development of their albedo climatology. Because the spectral variation of cloud transmittance is correlated with the spectral variation of sea ice albedo, we compute two different broadband albedo values for each surface, for use under clear or cloudy sky.

Figure 3 shows the distribution of surface albedo in spring and summer for four sample grid boxes spanning the latitude range of the sea ice zone in the South $\mathrm{Pa}$ cific and Ross Sea. The leftmost bin, albedo 0.0-0.1, is occupied by open water. The zone $50^{\circ}-52.5^{\circ} \mathrm{S}$ is ice free in both seasons; the other zones undergo substantial melting between spring and summer.

Zonal averages of these surface albedos for both clear and cloudy conditions are shown in Fig. 4. The albedo increases with latitude to a maximum near $75^{\circ} \mathrm{S}$, then decreases toward the fronts of the Filchner-Ronne and Ross Ice Shelves. [South of $75^{\circ} \mathrm{S}$, these are the only longitudes that contain ocean.] The average albedos are lower at the southern limit because the sea ice at the front of the ice shelf is blown to the north by southerly winds, exposing areas of open water.

The broadband solar albedo of sea ice under clear sky is lower than under cloud by 3\%-7\% (Brandt et al. 2005) because the albedos of snow and ice are lower in the near-infrared than in the visible and clouds absorb near-infrared radiation. However, this is not true for open water; its albedo is nearly constant with wavelength. On the other hand, water albedo increases sig- 
spring (SON)

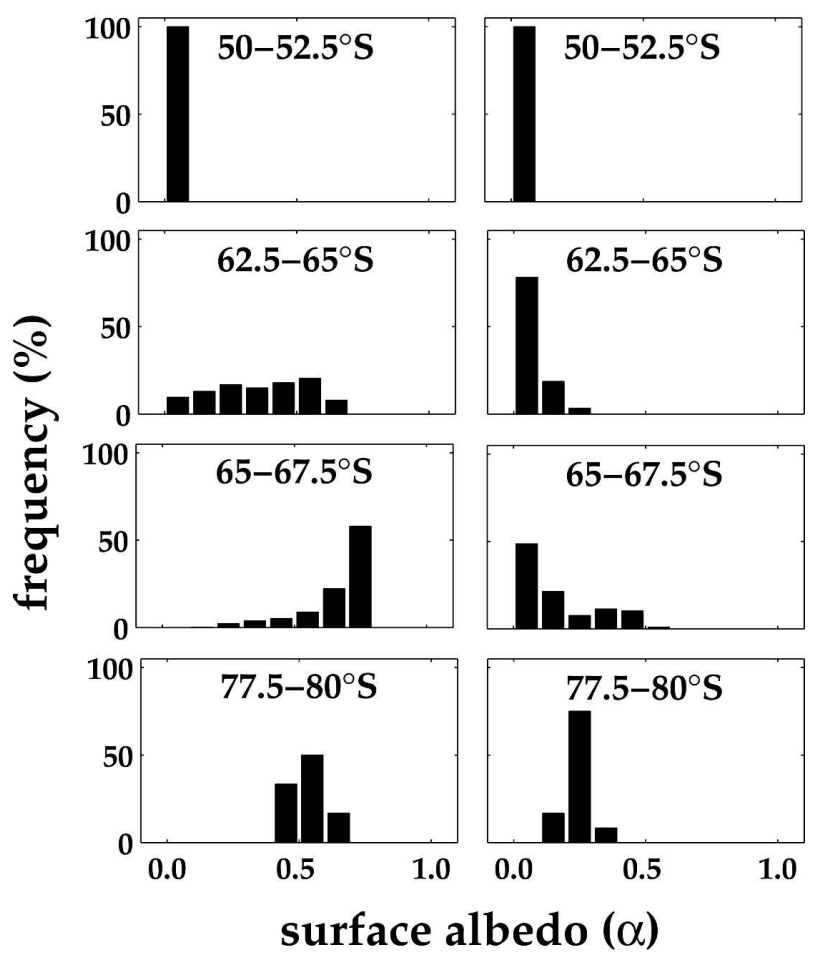

FIG. 3. Frequency distribution of surface albedo in spring and summer for four grid boxes spanning the latitudes of the sea ice zone. Average broadband solar albedos were determined from ice-only albedos together with satellite-derived ice concentrations as described in the text. The examples shown are in a single longitude sector, $120^{\circ}-160^{\circ} \mathrm{W}$, on the eastern side of the Ross Sea.

nificantly with solar zenith angle. When the sun is low, the broadband solar albedo of the sea surface under clear sky is therefore higher than under cloud. Only for solar zenith angles $<50^{\circ}$ is the albedo under clear sky equal to or slightly lower than that under cloud. For open water under clear sky we use the parameterization of Briegleb and Ramanathan (1982), which is based on observations by Payne (1972), and accounts for windinduced waves:

$$
\alpha=\frac{0.05}{\left(1.1 \mu_{o}^{1.4}+0.15\right)}
$$

where $\mu_{o}$ is the cosine of the solar zenith angle. The albedo values shown in Fig. 4 are the net result of all these effects calculated using the distributions of solar zenith angle described in the next section. The results show higher albedo under clear sky for water, but lower albedo under clear sky for ice and snow. (We are thus implicitly assuming that there is no correlation between $\tau$ and $\alpha$.)

\section{c. Distributions of solar zenith angle}

We derived distributions of solar zenith angle $\theta$ for each season by computing $\theta$ at half-hourly intervals throughout the season. We actually used a solar ephemeris that was obtained from R. Stephenson (University of Durham, 1993, personal communication) and used by Hahn et al. (1995). However, we have compared it with the published algorithm of Michalsky (1988), and it agrees well. Figure 5 shows frequency histograms of $\cos \theta$ for three different latitude bands in spring.

\section{Results-Cloud radiative forcing}

As discussed by FBW04 and FW05, the effective cloud optical depth $\tau$ is a convenient intermediate quantity used to predict cloud radiative effects. In FBW04 we developed a parameterization for cloud transmittance trc as a function of $\tau, \alpha$, and $\theta$ and used it to infer $\tau$, which is meant to be an inherent property of the cloud field that, unlike the transmittance, would be independent of solar zenith angle and local surface albedo. The parameterization, related to one by Wiscombe (1975), is

$$
\operatorname{trc}=\frac{a(\tau)+b(\tau) \cos \theta}{1+(c-d \alpha) \tau} .
$$

This parameterization takes into account the variation with wavelength of the optical properties of clouds, snow, and sea ice. For a thorough description of its physical basis and the derivation of the coefficients $(a$, $b, c, d$ ), see FBW04. We now use Eq. (4) to compute what the transmittance of the observed optical-depth distributions will be under different conditions of solar illumination and surface albedo. We calculate cloud transmittance values for each season and grid box using the appropriate distributions of $\tau, \alpha$, and $\theta$. We compute trc for each possible combination of $(\tau, \alpha, \theta)$, stepping in units $\Delta \tau=2$ (from $\tau=0$ to $\tau=60$ ), $\Delta \alpha=$ $0.1, \Delta \cos \theta=0.1$.

In Fig. 7 of FBW04 we showed that lack of knowledge of cloud-droplet effective radius in the derivation of $\tau$ and the subsequent prediction of trc results in errors of about $2 \%$ in trc. In addition, surface albedos derived from visual ice observations are typically uncertain to \pm 0.06 , and we estimated that this error also translates to errors of about $2 \%$ in trc. Together with the $1 \%-2 \%$ rms errors in the parameterization compared with the radiative transfer model, our estimate of errors in tre is about $5 \%$. However, the total error is probably instead dominated by errors in the cloudoptical-depth distributions, which would be more accurate if more pyranometer observations were available.

Some examples of frequency distributions of the resulting trc values are shown in Fig. 6. Most of the values 


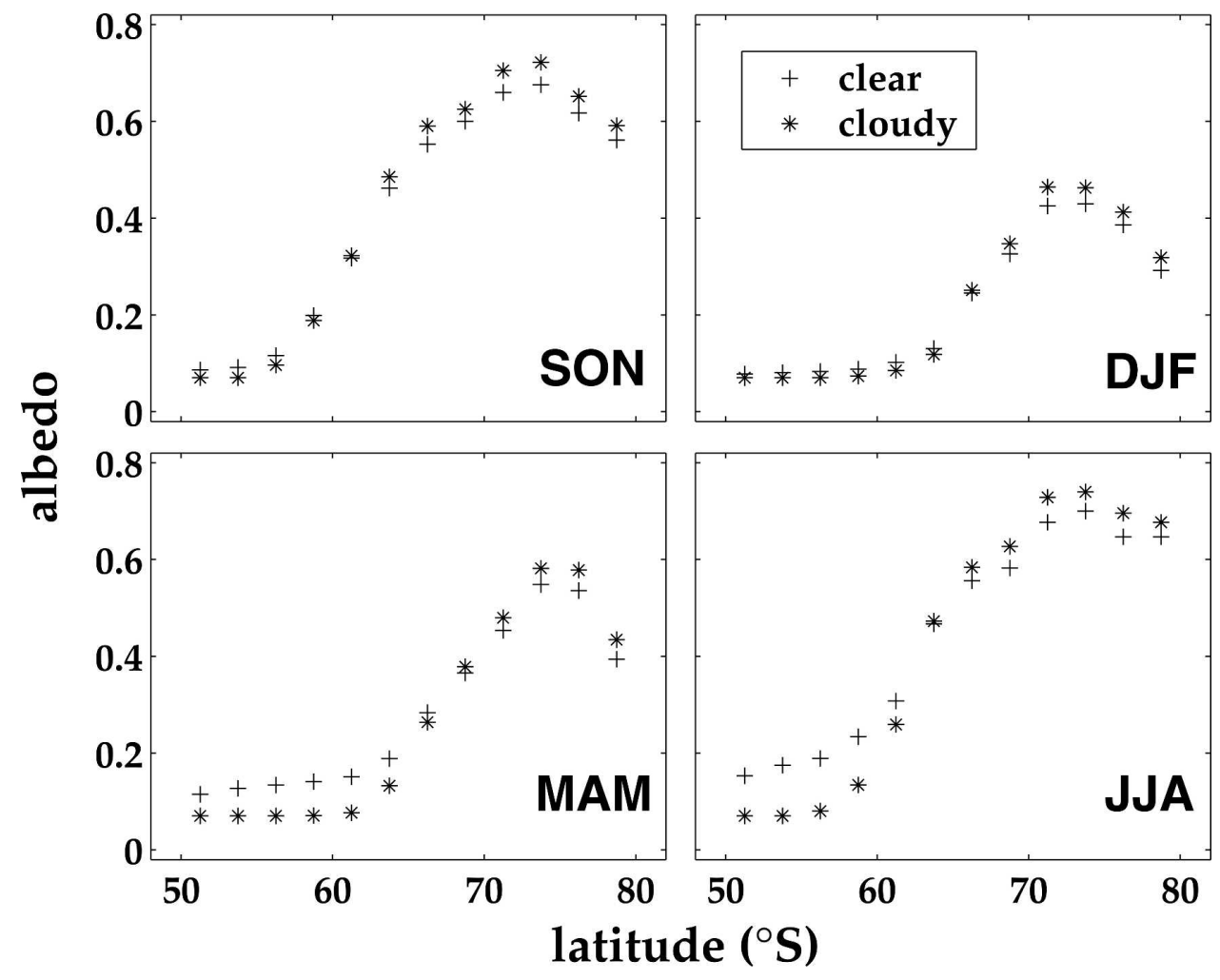

FIG. 4. Zonal-average broadband solar albedos for clear and overcast conditions as a function of latitude. For ice-free areas under clear sky, the albedo is a function of solar zenith angle [Eq. (3)].

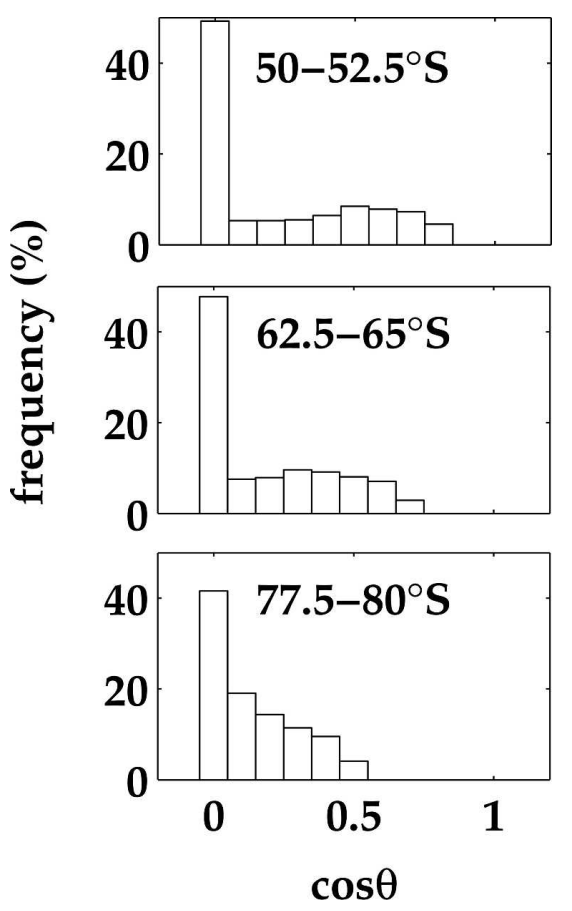

FIG. 5. Distribution of solar zenith angle in spring for 3 of the 12 latitude zones used in the analysis. Nighttime values are included in the first bin $(\cos \theta=0)$. Bin size is 0.1 units of cosine.

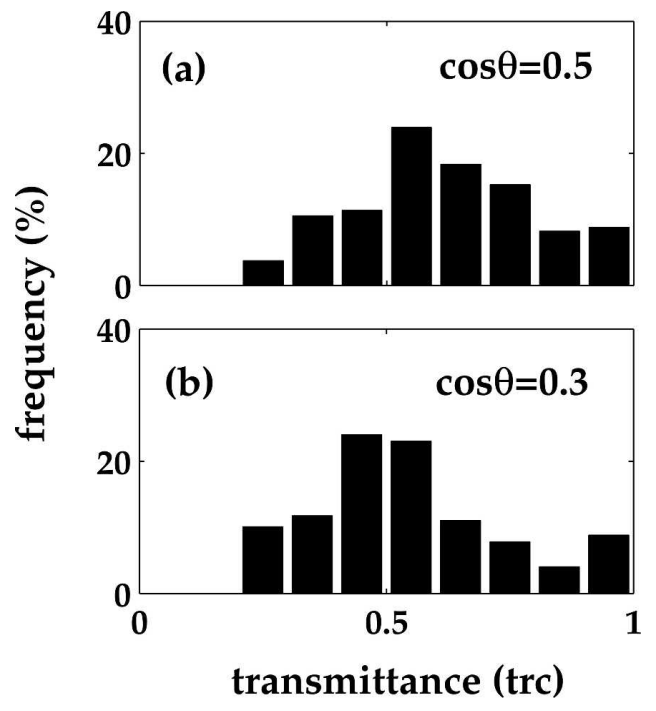

FIG. 6. Example of the frequency distribution of derived cloud transmittance trc determined using the parameterization [Eq. (4)], for two different solar zenith angles. The values shown are for a single latitude interval $\left(62.5^{\circ}-65^{\circ} \mathrm{S}\right)$ and a single longitude sector $\left(30^{\circ}-60^{\circ} \mathrm{E}\right)$ in spring $(\mathrm{SON})$ using the appropriate frequency distributions of surface albedos and cloud optical depths. Transmittance values are higher for the case of a higher sun. The rightmost $\operatorname{bin}(\operatorname{trc}=1.0)$ is the frequency of occurrence of "clear sky", i.e., the fraction of time that the direct solar beam is not blocked by clouds. 
TABLE 1. Seasonal average value of the extraterrestrial solar constant used in the analysis.

\begin{tabular}{lcccc}
\hline \hline & \multicolumn{4}{c}{ Season } \\
\cline { 2 - 5 } & SON & DJF & MAM & JJA \\
\hline$Q_{s}\left(\mathrm{~W} \mathrm{~m}^{-2}\right)$ & 1378 & 1412 & 1362 & 1329 \\
\hline
\end{tabular}

of trc are in the range $0.2-1.0$, where trc $\approx 1.0$ represents "clear sky." The effect of solar zenith angle on the distribution of trc is shown by comparing results for two different times of day. For the two examples, we use the same latitude, the same distribution of springtime surface albedos, and the same cloud optical depth distributions in our parameterization, but different solar zenith angles. The figure shows that trc values are higher for the case of a higher $\operatorname{sun}\left(\theta=60^{\circ}, \cos \theta=0.5\right)$. The increased pathlength at low sun, even through thin clouds, decreases the SW irradiance reaching the surface and hence decreases the transmittance.

The effect of clouds on the radiation budget is normally called "cloud radiative forcing," although it might more accurately be referred to as "cloud radiative effect" since "forcing" in other contexts means a change in radiative flux (due to an external influence on the system, often specifically anthropogenic contributions) rather than the climatological baseline. Here we use the standard term $(\mathrm{CRF})$, with its standard definition: the difference in irradiance between all conditions and clear conditions. To extend our dataset seasonally and geographically we take the values of cloud transmittance derived from each of the seasonal sets of distributions and calculate the downward SW cloud radiative forcing, $\mathrm{CRF}_{d}$; that is, the reduction in downward SW irradiance relative to clear sky. The downward SW irradiance at the surface, $F_{d s f c}$, under clear and cloudy skies at solar zenith angle $\theta_{k}$, is

$$
\begin{aligned}
F_{d \mathrm{sfc}}(\text { clear }) & =Q \cos \theta_{k} t_{\mathrm{clr} k} ; \\
F_{d \mathrm{sfc}}(\text { cloud }) & =Q \cos \theta_{k} t_{\mathrm{clr} k} \mathrm{trc},
\end{aligned}
$$

where $Q$ is the extraterrestrial solar irradiance, taken as a mean value for each season (Table 1 ), and $t_{\text {clr }}$ is clearsky transmittance. The instantaneous effect of a cloud (of optical thickness $\tau_{i}$ over a surface with albedo $\alpha_{j}$ ) is then

$$
\left(\mathrm{CRF}_{d}\right)_{i j k}=Q \cos \theta_{k}\left(\operatorname{trc}_{i j k}-1\right) t_{\mathrm{clr} k} .
$$

As explained in FW05, clear-sky transmittance is the downward irradiance under clear sky divided by $Q \cos \theta_{k}$, where $Q$ is the extraterrestrial solar irradiance for that day (which varies over the year because of variation of the earth-sun distance). The clear-sky transmittance was determined experimentally from springtime shipboard measurements of downwelling irradiance under clear skies (Fig. 7 of FW05); FW05 found the data to be adequately fitted by a linear function over the range of zenith angles encountered $\left(50^{\circ}-80^{\circ}\right)$ :

$$
t_{\mathrm{clr}}(\theta)=1.03-0.0046 \theta,
$$

where $\theta$ is in degrees. By comparing clear-sky measurements from several voyages, we estimate that our experimental clear-sky transmittance varies by less than $3 \%$ between the spring and summer seasons. The differences may be due to changes in ozone and water vapor amounts. We use the springtime linear fit of Eq. (7) for all seasons in our computations because it has the most reliable records of clear sky from the ship's meteorological observers and it adequately approximates the clear-sky transmittance in summer.

Equation (6) is used for each value of trc at a given solar zenith angle $\theta_{k}$, obtained from the various combinations of $\alpha$ and $\tau$, including $\tau=0$; then the individual values of CRF are averaged according to their weights. The sum goes over both day and night; at night we set $\cos \theta_{k}=0$ (Fig. 5). The seasonal average value of downward cloud radiative forcing, $\mathrm{CRF}_{d}$, is then

$$
\mathrm{CRF}_{d}=\frac{\sum_{i} \sum_{j} \sum_{k} \mathrm{CRF}_{d, i j k} f_{i} f_{j} f_{k}}{\sum_{i} \sum_{j} \sum_{k} f_{i} f_{j} f_{k}},
$$

where $f_{i}, f_{j}$, and $f_{k}$ are the bin values in the frequency histograms of $\tau, \alpha$, and $\theta$ for the particular season and grid box. The denominator of (8) is therefore 1.0.

The net SW cloud radiative forcing at the surface, $\mathrm{CRF}_{n}$, is the difference in net shortwave irradiance between all conditions and clear conditions. It is obtained by multiplying $\mathrm{CRF}_{d}$ by the coalbedo $(1-\alpha)$ :

$$
\mathrm{CRF}_{n, i j k}=\left(1-\alpha_{j}\right) \mathrm{CRF}_{d, i j k} \text {. }
$$

We calculate $\mathrm{CRF}_{d}$ and $\mathrm{CRF}_{n}$ for three different cases of surface and sky conditions. The three cases are meant to represent present conditions and hypothetical conditions of changed climate. They are (i) the present sea ice and cloud climatology (PIC), (ii) no sea ice but with the same present cloud climatology (NIC), and (iii) no sea ice but with uniform cloud south of $60^{\circ} \mathrm{S}$ of the same thickness as presently in the latitude band with thickest clouds $\left(55^{\circ}-60^{\circ} \mathrm{S}\right.$; NITH). Case (iii) thus represents a likely upper bound of resulting cloud distributions if sea ice were to disappear in a warmer climate. Case (ii) is not a lower bound because clouds might actually diminish in the sea ice zone, if sea ice were to disappear, due to changes in atmospheric dynamics. 


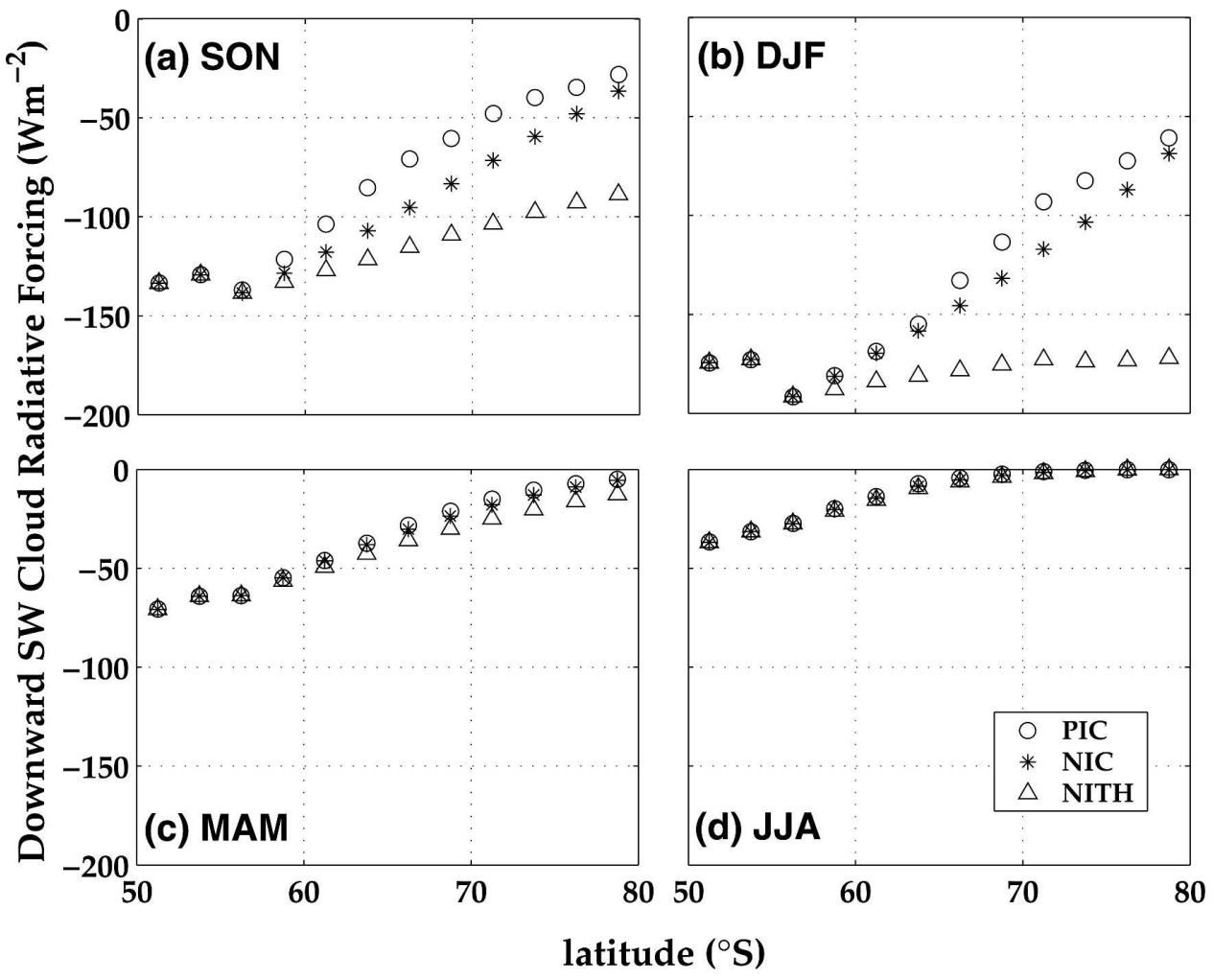

FIG. 7. Downward shortwave cloud radiative forcing $\left(\mathrm{CRF}_{d}\right)$, i.e., the change in downward shortwave irradiance at the surface, as a function of latitude for three different cases of surface and sky conditions. The three cases are PIC (present ice and cloud), NIC (no ice and present cloud), and NITH (no ice and thick cloud).

Figure 7 shows the zonal averages of $\mathrm{CRF}_{d}$ as functions of latitude for these three cases while Fig. 8 shows the same for $\mathrm{CRF}_{n}$. For present conditions, $\mathrm{CRF}_{n}$ in spring ranges from $-130 \mathrm{~W} \mathrm{~m}^{-2}$ over the ocean to -10 $\mathrm{W} \mathrm{m}{ }^{-2}$ over the ice; and in summer from -180 to -45 $\mathrm{W} \mathrm{m}{ }^{-2}$, respectively. $\mathrm{CRF}_{n}$ is smaller in magnitude if ice is present, because ice reflects much of the sunlight even if clouds are absent. $\mathrm{CRF}_{d}$ is also slightly smaller, if ice is present, because of multiple reflection between the surface and the cloud base.

\section{Results-Surface irradiance}

Some climate models suggest that sea ice extent may be substantially reduced in the Southern Ocean with global warming (Hunt et al. 1995, Bromwich et al. 1998). Because sea ice plays an important role in both the oceanic and atmospheric circulations, variations in its areal extent may lead to large-scale, long-term climate change. While no uniform trend in Antarctic sea ice extent has been detected by satellite data over the last four decades (Jacka and Budd 1998; Wu et al. 1999; Worby and Comiso 2004), several studies (Gloersen et al. 1992; Stammerjohn and Smith 1997; Ackley et al. 2003) do point to regional and contrasting variations in sea ice extent in the Southern Ocean. For example, using satellite data, Zwally et al. (2002) calculated an increase in sea ice extent in the Weddell, Pacific, and Ross sectors of $1.4 \%, 2.0 \%$, and $6.7 \%$ per decade, and a decrease in the Indian and Bellingshausen-Amundsen sectors of $-1.0 \%$ and $-9.7 \%$ per decade, respectively, over the period 1979-98. However, as Worby and Comiso (2004) showed, discrepancies in the location of the ice edge between ship and satellite measurements are as great as 1-2 degrees of latitude, with the poorest correlations during the spring and summer melt season. Thus, to date, there is no clear evidence for an increase or decrease of total sea ice extent in the Southern Ocean as a result of the past century of global warming. Goosse and Renssen (2005) used a climate model driven by natural and anthropogenic forcings to simulate sea ice extent over the last several hundred years. They concluded that the ice area has decreased by about $8 \%\left(0.75 \times 10^{6} \mathrm{~km}^{2}\right)$ in its annual mean over the last 150 years, but the changes are too slow to detect from the 25 -yr satellite record. Further reductions can 


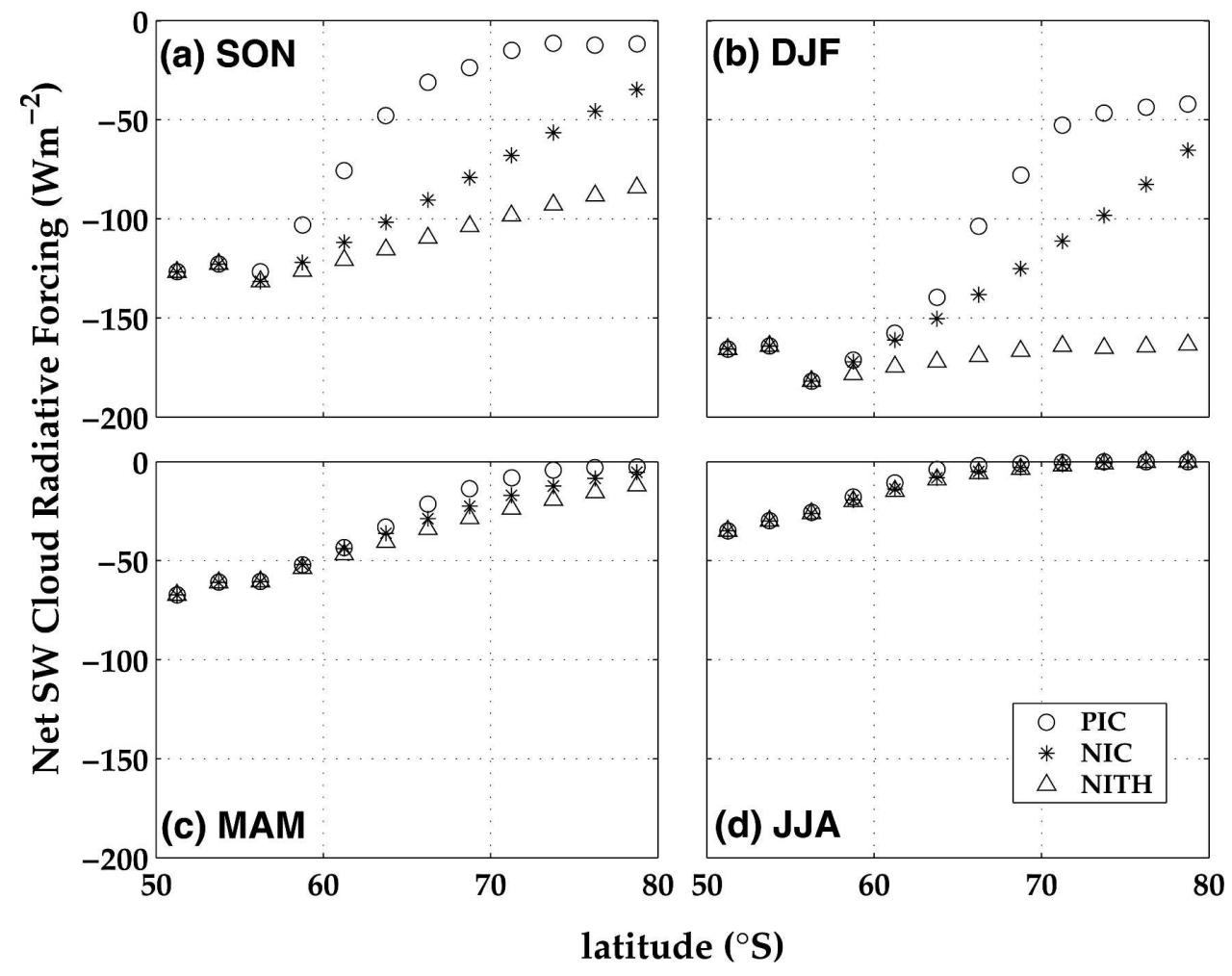

FIG. 8. Net shortwave cloud radiative forcing $\left(\mathrm{CRF}_{n}\right)$ at the surface obtained by multiplying the downward shortwave cloud radiative forcing from Fig. 7 by $(1-\alpha)$, where $\alpha$ is the surface albedo. The three cases are PIC, NIC, and NITH. The larger values of $\mathrm{CRF}_{n}$ in summer than in spring are due to the lower surface albedo.

be expected this coming century due to the delayed response of the Southern Ocean to anthropogenic warming.

In our present study, we consider the extreme of the complete removal of sea ice from the Southern Ocean. Sea ice may have two different effects on the solar radiation budget: first and most obvious, it reduces the solar heating of the ocean by raising the local surface albedo; second and more speculative, it may inhibit cloud formation by suppressing the exchange of heat and moisture between the ocean and the atmosphere (King and Turner 1997). With our data we can calculate the change in SW fluxes that would result if either the cloud cover or the sea ice were removed. To determine this we calculate seven different fluxes below and compare them.

\section{a. Surface irradiance calculations}

The top of the atmosphere (TOA) downward SW irradiance is calculated using

$$
F_{d \text { toa }}=Q\langle\cos \theta\rangle
$$

and

$$
\langle\cos \theta\rangle=\sum_{k} f_{k}(\cos \theta)_{k},
$$

where $f_{k}$ is the frequency of occurrence of zenith angle $\theta_{k}$ as shown in the examples, Fig. 5. The downward SW irradiance at the surface under clear sky is given by

$$
F_{d \mathrm{sfc}}=Q\left\langle t_{\mathrm{clr}} \cos \theta\right\rangle
$$

and

$$
\left\langle t_{\mathrm{clr}} \cos \theta\right\rangle=\sum_{k} t_{\mathrm{clr} k} f_{k}(\cos \theta)_{k},
$$

where $t_{\mathrm{clr} k}$ is the value of $t_{\mathrm{clr}}$ at solar zenith angle $\theta_{k}$. The net irradiance under clear sky, $F_{n \mathrm{ncl}}$, is simply given by the downward irradiance decreased by the amount reflected by the surface as

$$
F_{n \mathrm{clr}}=F_{d \mathrm{sfc}}(1-\alpha) ;
$$

$F_{n \text { clr }}$ is calculated for either ice or no ice using the zonally averaged albedos from Fig. 4. Using zonally averaged $\mathrm{CRF}_{n}$ values obtained from the distributions of $\tau$, $\alpha$, and $\theta$ for each of the three cases of surface and sky conditions, we calculate the net irradiance for all conditions, $F_{n a l l}$, at the surface as the sum of the net irra- 


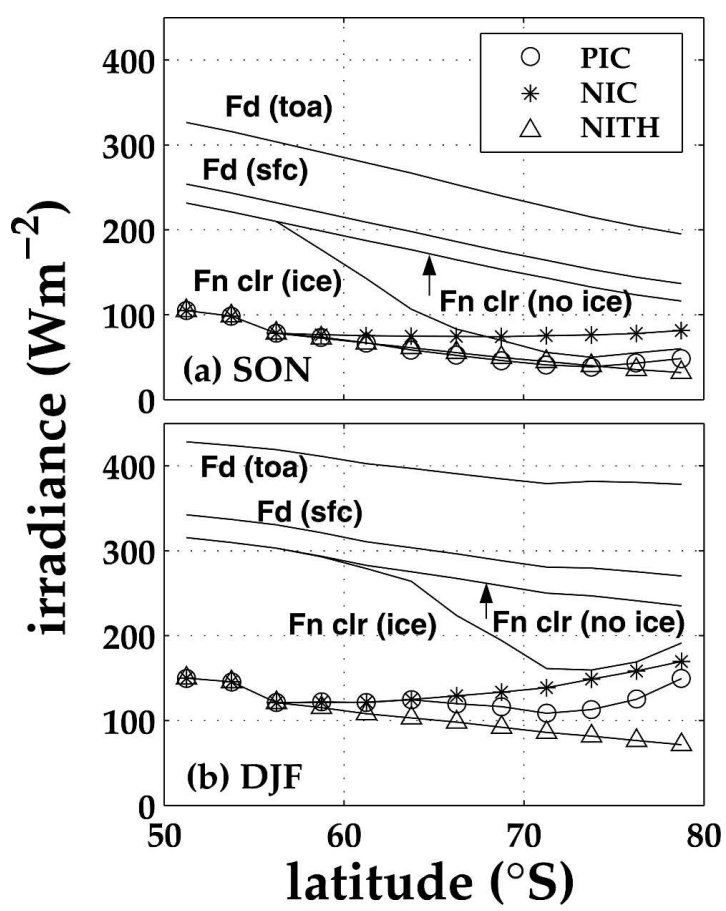

FIG. 9. Effect of varying surface and sky conditions on the net shortwave irradiance at the surface in (a) spring and (b) summer. The downward irradiance at the top of atmosphere, Fd(toa), and at the surface, $\mathrm{Fd}(\mathrm{sfc})$, are shown for reference. The clear-sky net irradiance is shown for both water (NI) and ice (I) surfaces, as well as the net irradiance for three different cases: PIC, NIC, and NITH.

diance at the surface (for clear sky) and the cloud radiative forcing (which for SW radiation is negative) from

$$
\mathrm{CRF}_{n}=F_{n \text { all }}-F_{n \text { clr }} .
$$

These seven irradiance values $-F_{d \text { toa }}, F_{d \mathrm{sfc}}, F_{n \mathrm{clr}}$ (ice, no ice), and $F_{n \text { all }}$ (PIC, NIC, NITH) - are plotted as functions of latitude in Fig. 9 for the two seasons of high sun.

In spring (Fig. 9a), cloud makes a greater contribution to surface cooling than does ice between $50^{\circ}$ and about $68^{\circ} \mathrm{S}$, with values of $F_{n \text { all }}$ (NIC) close to 100 $\mathrm{Wm}^{-2}$ over most latitudes. South of $68^{\circ} \mathrm{S}$ this switches, and ice contributes more to decreasing incoming radiation than cloud does, with $F_{n \text { clr }}$ (ice) dropping to as low as $50 \mathrm{Wm}^{-2}$ at high latitudes. \{Starting with $F_{n \text { clr }}$ (no ice), adding either ice ["F ${ }_{n \text { clr }}$ (ice)"] or cloud ["F ${ }_{n \text { cld }}$ (no ice)"], but not both, gives equal values of $\mathrm{F}_{n}$ at latitude $68^{\circ} \mathrm{S}$.\} Comparison of the net irradiance for the three different cases, PIC, NIC, and NITH, shows that in spring, at latitudes poleward of $60^{\circ} \mathrm{S}$, regardless of the type of cloud remaining, removing sea ice results in an increase in irradiance reaching the surface. Thus the present combination of sea ice and cloud cover has a greater cooling effect than the case of no ice with either present cloud or thick cloud. However, in summer (Fig. $9 \mathrm{~b})$ the removal of ice results in higher irradiance at the surface only if clouds remain unchanged. If clouds become as thick as those presently over the ocean at $55^{\circ}-$ $60^{\circ} \mathrm{S}$, irradiance reaching the ground in summer decreases poleward of $65^{\circ} \mathrm{S}$.

\section{b. Effect of present clouds and ice}

We now consider the relative importance of the modern climatological ice and cloud to the radiation budget by taking differences between pairs of curves in Fig. 9 . Figure 10 shows the difference, $\Delta F_{C}$, between net irradiance for condition $C$ and net irradiance for no ice and clear sky, given by

$$
\Delta F_{C}=F_{n C}-F_{n} \text { (clear, no ice), }
$$

where subscript $C$ is PIC, NIC, or NITH. We also plot the difference, $\Delta F_{\mathrm{ICE}}$, between net irradiance for ice and no ice under clear sky:

$$
\Delta F_{\text {ICE }}=F_{n}(\text { clear, ice })-F_{n}(\text { clear, no ice }) .
$$

Figure 10 shows these changes in surface irradiance from a baseline of ice-free, cloud-free conditions for each season. We evaluate the relative importance of ice and cloud by comparing $\Delta F_{\mathrm{ICE}}$ with $\Delta F_{C}$ for the three cases of PIC, NIC, and NITH. Figure 10a shows that, in spring, ice makes a larger contribution to cooling poleward of $67^{\circ} \mathrm{S}$ than does present cloud on its own, but a smaller contribution than a change to thick cloud at all latitudes. Figure 10b shows that, in summer, the contribution of either present cloud or thick cloud to cooling is greater than for present ice at all latitudes. We calculate the mean values of $\Delta F_{\text {ICE }}$ for the latitudes where sea ice occurs presently, accounting for change in zonal area and for fraction of ocean at each latitude. These are shown in Table 2.

\section{c. Climate change scenarios}

Figure 11 shows the change in net surface irradiance, if sea ice is completely removed, as

$$
\Delta F_{P}=F_{n \text { all(NIC/NITH) }}-F_{n \text { all(PIC) }} .
$$

The two cloud scenarios we consider for the case of no ice are (i) the present cloud climatology and (ii) a cloud climatology with the current thickest cloud band extending over the entire Southern Ocean southward of $60^{\circ} \mathrm{S}$. Thus the envelope between NIC and NITH in Fig. 11 gives an indication of the likely bounds of the response of surface irradiance to the disappearance of sea ice. 


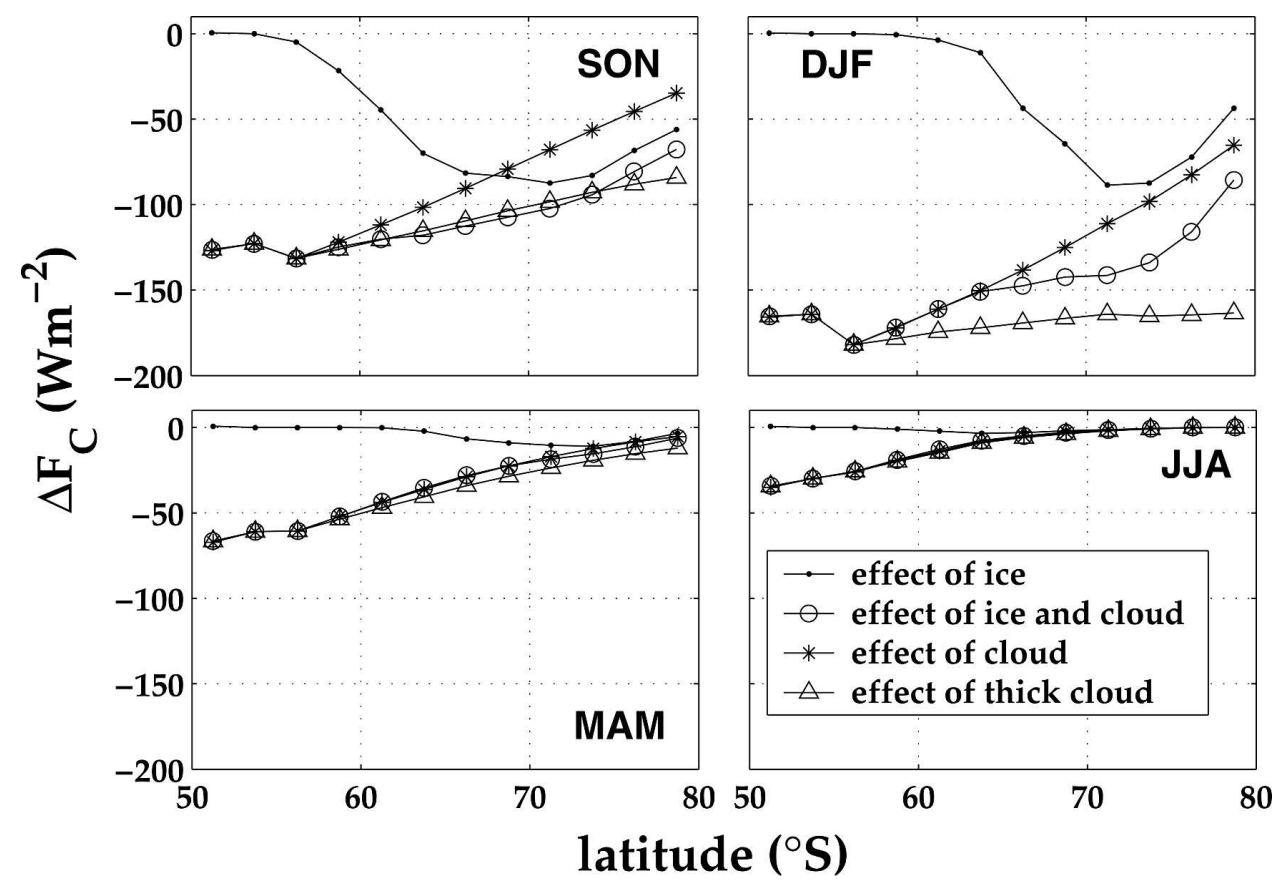

FIG. 10. Change in net shortwave surface irradiance (in $\mathrm{W} \mathrm{m}^{-2}$ ) compared with ice-free, cloud-free conditions for each season. $\Delta F_{\text {ICE }}$ is the difference between net irradiance for ice and no ice under clear sky. The other three lines are differences for each of the three cases: PIC, NIC, and NITH.

In spring (Fig. 11a), removing the sea ice leads to a change in net SW surface irradiance ranging from +35 to $-10 \mathrm{~W} \mathrm{~m}^{-2}$ depending on latitude and cloud optical depths. Positive values (indicating a surface warming compared to the present) occur in both cases (NIC and NITH) at latitudes between approximately $60^{\circ}$ and $75^{\circ} \mathrm{S}$. Farther south the "thick cloud" case results in a cooling effect. Figure $11 \mathrm{~b}$ shows that, in summer, the envelope is bounded by +35 and $-70 \mathrm{~W} \mathrm{~m}^{-2}$, but in this figure the thick cloud scenario (NITH) leads to cooling at all latitudes. The effects in autumn and winter (Figs. 11c,d) are small because there is little sunlight.

Table 3 gives the average change in net SW irradiance, $\Delta F_{P}$, for the two cases (NIC and NITH) compared to present climatic conditions. Here $\Delta F_{P}$ is calculated accounting for the area of each zone and for fraction of ocean in each zone. If sea ice is removed but

TABLE 2. Area-average effects of present sea ice and present clouds on the net shortwave radiation at the surface. Mean values, weighted by zonal area and zonal ocean fraction, are calculated for latitudes $57.5^{\circ}-77.5^{\circ} \mathrm{S}$. The units are $\mathrm{W} \mathrm{m}^{-2}$.

\begin{tabular}{lrr}
\hline \hline & SON & DJF \\
\hline Sea ice alone $\left(\Delta F_{\text {ICE }}\right)$ & -60 & -30 \\
Clouds alone $\left(\Delta F_{\text {NIC }}\right)$ & -90 & -130 \\
Sea ice + clouds $\left(\Delta F_{\text {PIC }}\right)$ & -115 & -150 \\
\hline
\end{tabular}

cloud amount and optical-depth distribution remain at their present values, spring and summer show an increase of shortwave into the Southern Ocean of 17 and $8 \mathrm{~W} \mathrm{~m}^{-2}$, respectively. If, however, clouds adopt a new climatology of the current thickest cloud zone in the Southern Ocean, removing sea ice results in almost no change to the SW radiation budget in spring and a cooling of $20 \mathrm{~W} \mathrm{~m}^{-2}$ in summer.

We are skeptical that such a widespread increase in cloud optical thickness would result. Our own data dispute this possibility; as mentioned above, we found no significant difference in cloud cover or cloud thickness between ice-covered and ice-free regions at the same latitude. Furthermore, the thick clouds at $55^{\circ}-60^{\circ} \mathrm{S}$ may be the result of storm systems generated at the sea ice margin; if the sea ice margin moves south, the zone of thick clouds may just move south rather than increasing its latitudinal extent. We therefore present the NITH case as an upper limit, not as a realistic scenario.

\section{Conclusions}

Distributions of cloud optical depth were used, together with distributions of surface albedo, to estimate the geographical and seasonal variations of shortwave irradiance and cloud radiative forcing at the surface in the Southern Ocean for latitudes $50^{\circ}-80^{\circ} \mathrm{S}$. Using a pa- 


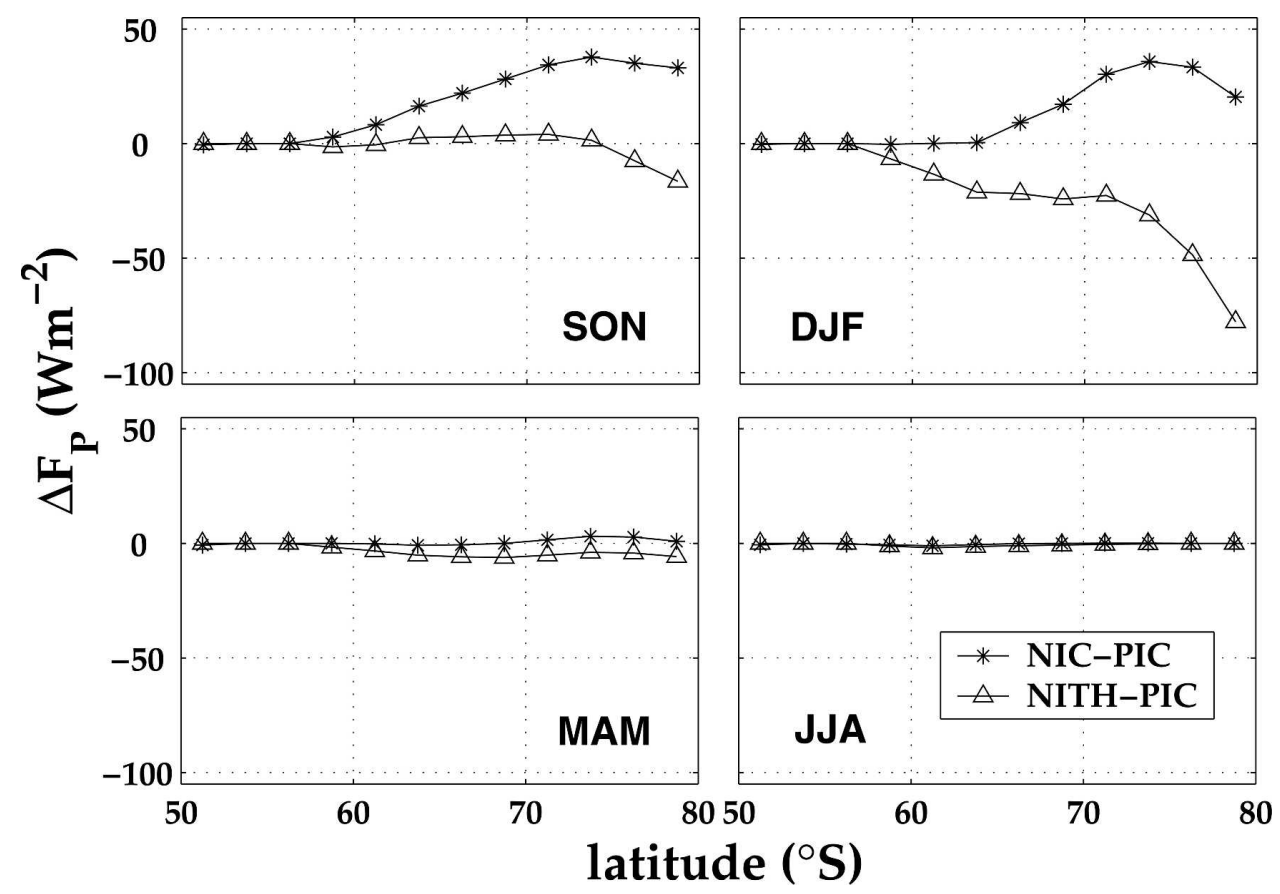

FIG. 11. Change in net shortwave surface irradiance (in $\mathrm{W} \mathrm{m}^{-2}$ ) if sea ice is removed from the Southern Ocean, shown for each season. Comparison is with present climatic conditions of ice and cloud (PIC). The envelope between the two lines gives the probable bounds of change in cloud distribution.

rameterization developed in earlier work, estimates based on surface observations were made both for the present climate and for altered surface and cloud conditions. Latitudinal and zonal-average quantities were calculated.

The relative importance of sea ice and cloud in the solar radiation budget was determined by removing either sea ice or cloud, applying the parameterization with these new climatologies, and then computing the changes to the surface irradiance. In summer the clouds are more important for the radiation balance than sea ice at all latitudes in the Southern Ocean. However, in spring sea ice has a greater cooling effect than clouds south of $67^{\circ} \mathrm{S}$.

TABLE 3. Mean change in net shortwave irradiance at the surface (in $\mathrm{W} \mathrm{m}^{-2}$ ) resulting from complete removal of sea ice for two different assumptions of cloud characteristics as a function of latitude. The mean (weighted by zonal area and ocean fraction) is calculated for latitudes $57.5^{\circ}-77.5^{\circ} \mathrm{S}$ for the differences shown in Fig. 11. Positive values represent warming.

\begin{tabular}{llrrrr}
\hline \hline & SON & DJF & MAM & JJA \\
\hline$\Delta F_{P(\text { NIC })}$ & $\begin{array}{c}\text { (No ice, present cloud) }- \\
\text { present }\end{array}$ & 17 & 8 & 0 & 0 \\
$\Delta F_{P(\text { NITH })}$ & $\begin{array}{l}\text { No ice, thick cloud) }- \\
\text { present }\end{array}$ & 0 & -20 & -4 & 0 \\
&
\end{tabular}

We also investigated a scenario in which loss of sea ice results in thicker clouds. Compared to the present climate in spring, removing sea ice results in an increase in irradiance reaching the ocean surface, regardless of the type of cloud remaining. However, in summer the removal of sea ice results in higher irradiance at the surface only if clouds remain unchanged; if clouds thicken, they reduce the solar heating of the ocean more than does the present summer sea ice. In a warming climate, the effect of a reduction in summer sea ice extent will greatly depend on the type and thickness of clouds that arise from the increased transfer of heat and moisture from the ocean to the atmosphere. Net shortwave cloud radiative forcing increases in magnitude by up to $80 \mathrm{~W} \mathrm{~m}^{-2}$ in spring and $120 \mathrm{~W} \mathrm{~m}^{-2}$ in summer with a removal of sea ice. These results highlight the importance of understanding feedback mechanisms in the current climate system and how they will be altered in a warmer world.

This study is an initial attempt at quantifying the effects of sea ice and clouds on the climate of the Southern Ocean. The data used come mostly from the East Antarctic sector, but with plausible assumptions the cloud properties have been extended to other sectors. The use of broadband pyranometers rather than spectral radiometers was intentional. Because these lowcost instruments are widely used, the same methods 
that we have developed (in FBW04 and FW05) could potentially be applied in other oceans to give a greater coverage of surface-derived cloud optical properties. The technique could also be repeated for the cloud-top surface and compared with retrievals of top-of-atmosphere radiative properties. The present results may be useful as input to general circulation models, or for testing predictions of those models. They can also be compared to values of cloud radiative forcing and surface irradiance derived from satellite measurements.

Acknowledgments. Cloud observations were obtained from the Comprehensive Ocean-Atmosphere Data Set (COADS) provided by the National Center for Atmospheric Research and the National Oceanic and Atmospheric Administration; Scott Woodruff provided assistance in accessing these data. Cloud observations archived by the Commonwealth Bureau of Meteorology were also used; we thank Ian BarnesKeoghan and Doug Shepherd. Sea ice observations were obtained from the Australian Antarctic Division Data Centre as part of the Antarctic Sea Ice Processes and Climate (ASPeCt) program; we thank Richard Brandt from the University of Washington, who provided his programs and expertise to calculate sea ice albedos. This work was supported by NSF Grants OPP95-27244, OPP-98-15156, and OPP-00-03826, and by a NASA Earth System Science Fellowship to Melanie Fitzpatrick. We also thank two anonymous reviewers for helpful comments that improved the clarity of our paper.

\section{REFERENCES}

Ackley, S., P. Wadhams, J. C. Comiso, and A. P. Worby, 2003: Decadal decrease of Antarctic sea ice extent inferred from whaling records revisited on the basis of historical and modern sea ice records. Polar Res., 22, 19-25.

Barker, H. W., 1996: A parameterization for computing gridaveraged solar fluxes for inhomogeneous marine boundary layer clouds. Part I: Methodology and homogeneous biases. $J$. Atmos. Sci., 53, 2289-2303.

— - T. J. Curtis, E. Leontieva, and K. Stamnes, 1998: Optical depth of overcast cloud across Canada: Estimates based on surface pyranometer and satellite measurements. J. Climate, 11, 2980-2994.

Brandt, R. E., S. G. Warren, A. P. Worby, and T. C. Grenfell, 2005: Surface albedo of the Antarctic sea ice zone. J. Climate, 18, 3606-3622.

Briegleb, B., and V. Ramanathan, 1982: Spectral and diurnal variations in clear sky planetary albedo. J. Appl. Meteor., 21, 1160-1171.

Bromwich, D. H., B. Chen, K. M. Hines, and R. I. Cullather, 1998: Global atmospheric responses to Antarctic forcing. Ann. Glaciol., 27, 521-527.

Comiso, J. C., 1986: Characteristics of Arctic winter sea ice from satellite multispectral microwave observations. J. Geophys. Res., 91, 975-994.

_ cited 2002: Bootstrap sea ice concentrations for NIMBUS-7 SMMR and DMSP SSM/I. National Snow and Ice Data Center, Boulder, CO. [Available online at http://nsidc.org/data/ nsidc-0079.html.]

Fitzpatrick, M. F., and S. G. Warren, 2005: Transmission of solar radiation by clouds over snow and ice surfaces. Part II: Cloud optical depth and shortwave radiative forcing from pyranometer measurements in the Southern Ocean. J. Climate, 18, 4637-4648.

_, R. E. Brandt, and S. G. Warren, 2004: Transmission of solar radiation by clouds over snow and ice surfaces: A parameterization in terms of optical depth, solar zenith angle, and surface albedo. J. Climate, 17, 266-275.

Gloersen, P., W. J. Campbell, D. J. Cavalieri, J. C. Comiso, C. L. Parkinson, and H. Z. Zwally, 1992: Arctic and Antarctic sea ice, 1978-1987: Satellite passive-microwave observations and analysis. NASA SP-511, National Aeronautics and Space Administration, Washington, DC, $290 \mathrm{pp}$.

Goosse, H., and H. Renssen, 2005: A simulated reduction in Antarctic sea-ice area since 1750: Implications of the long memory of the ocean. Int. J. Climatol., 25, 569-579.

Hahn, C. J., S. G. Warren, and J. London, 1995: The effect of moonlight on observation of cloud cover at night, and application to cloud climatology. J. Climate, 8, 1429-1446.

Hall, A., 2004: The role of surface albedo feedback in climate. $J$. Climate, 17, 1550-1568.

Holland, M. M., and C. M. Bitz, 2003: Polar amplification of climate change in coupled models. Climate Dyn., 21, 221-232.

Hunt, B. G., H. B. Gordon, and H. L. Davies, 1995: Impact of greenhouse effect on sea-ice characteristics and snow accumulation in the polar regions. Int. J. Climatol., 15, 3-23.

Jacka, T. H., and W. F. Budd, 1998: Detection of temperature and sea-ice-extent changes in the Antarctic and Southern Ocean, 1949-96. Ann. Glaciol., 27, 553-559.

Kato, S., F. G. Rose, and T. P. Charlock, 2005: Computation of domain-averaged irradiance using satellite-derived cloud properties. J. Atmos. Oceanic Technol., 22, 146-164.

King, J. C., and J. Turner, 1997: Antarctic Meteorology and Climatology. Cambridge University Press, 409 pp.

Li, Z., and H. G. Leighton, 1991: Scene identification and its effect on cloud radiative forcing in the Arctic. J. Geophys. Res., 96, 9175-9188.

Mahesh, A., V. P. Walden, and S. G. Warren, 2001: Ground-based infrared remote sensing of cloud properties over the Antarctic Plateau. Part II: Cloud optical depths and particle sizes. J. Appl. Meteor., 40, 1279-1294.

Manabe, S., and R. J. Stouffer, 1980: Sensitivity of a global climate model to an increase of $\mathrm{CO}_{2}$ concentration in the atmosphere. J. Geophys. Res., 85, 5529-5554.

Michalsky, J. J., 1988: The Astronomical Almanac's algorithm for approximate solar position (1950-2050). Solar Energy, 40, 227-235.

Minnett, P. J., 1999: The influence of solar zenith angle and cloud type on cloud radiative forcing at the surface in the Arctic. $J$. Climate, 12, 147-158.

Pavolonis, M. J., and J. R. Key, 2003: Antarctic cloud radiative forcing at the surface estimated from the AVHRR Polar Pathfinder and ISCCP D1 datasets, 1985-93. J. Appl. Meteor., 42, 827-840.

Payne, R. E., 1972: Albedo of the sea surface. J. Atmos. Sci., 29, 959-970. 
Qu, X., and A. Hall, 2005: Surface contribution to planetary albedo variability in cryosphere regions. J. Climate, 18, 52395252.

Ramanathan, V., R. D. Cess, E. F. Harrison, P. Minnis, B. R. Barkstrom, E. Ahmed, and D. Hartmann, 1989: Cloudradiative forcing and climate: Results from the Earth Radiation Budget Experiment. Science, 243, 57-63.

Raschke, E., A. Ohmura, W. B. Rossow, B. E. Carlson, Y.-C. Zhang, C. Stubenrauch, M. Kottek, and M. Wild, 2005: Cloud effects on the radiation budget based on ISCCP data (19911995). Int. J. Climatol., 25, 1103-1125.

Rossow, W. B., and L. Dueñas, 2004: The International Satellite Cloud Climatology Project (ISCCP) Web site: An online resource for research. Bull. Amer. Meteor. Soc., 72, 2-20.

Stammerjohn, S. E., and R. C. Smith, 1997: Opposing Southern Ocean climate patterns as revealed by trends in regional sea ice coverage. Climatic Change, 37, 617-639.

Warren, S. G., C. J. Hahn, J. London, R. M. Chervin, and R. L. Jenne, 1988: Global distribution of total cloud cover and cloud type amounts over the ocean. NCAR Tech. Note TN317+STR, Boulder, CO, 42 pp. + 170 maps.

Wielicki, B. A., B. R. Barkstrom, E. F. Harrison, R. B. Lee, G. L. Smith, and J. E. Cooper, 1996: Clouds and the Earth's Radiant Energy System (CERES): An Earth Observing System experiment. Bull. Amer. Meteor. Soc., 77, 853-868.

Wiscombe, W. J., 1975: Solar radiation calculations for Arctic summer stratus conditions. Climate of the Arctic, G. Weller and S. A. Bowling, Eds., University of Alaska Press, 245-254.

Woodruff, S. D., H. F. Diaz, J. D. Elms, and S. J. Worley, 1998: COADS Release 2 data and metadata enhancements for improvements of marine surface flux fields. Phys. Chem. Earth, 23, 517-527.

Worby, A. P., 1999: Observing Antarctic Sea Ice: A Practical Guide for Conducting Sea-Ice Observations from Vessels Operating in the Antarctic Pack Ice. Australian Antarctic Division, CD-ROM.

_ and J. C. Comiso, 2004: Studies of the Antarctic sea ice edge and ice extent from satellite and ship observations. Remote Sens. Environ., 92, 98-111.

Worley, S. J., S. D. Woodruff, R. W. Reynolds, S. J. Lubker, and N. Lott, 2005: ICOADS Release 2.1 data and products. Int. J. Climatol., 25, 823-842.

Wu, X., W. F. Budd, and T. H. Jacka, 1999: Simulations of Southern Hemisphere warming and Antarctic sea-ice changes using global climate models. Ann. Glaciol., 29, 61-65.

Yamanouchi, T., and T. P. Charlock, 1997: Effects of clouds, ice sheet, and sea ice on the Earth radiation budget in the Antarctic. J. Geophys. Res., 102, 6953-6970.

Zwally, H. J., J. C. Comiso, C. L. Parkinson, D. J. Cavalieri, and P. Gloersen, 2002: Variability of Antarctic sea ice 1979-1998. J. Geophys. Res., 107, 3041, doi:10.1029/2000JC000733. 